\title{
O profissional de secretariado executivo como protagonista na proposição e gestão de projetos
}

\author{
The executive secretariat professional as protagonist in the proposal and management of \\ projects
}

\author{
Luciana Paula Bento Luciani $^{1(\mathrm{D})}$, Beatriz Naves da Silva Santos ${ }^{2}(\mathrm{D}$ \\ ${ }^{1}$ Fundação Escola de Comércio Álvares Penteado (FECAP), Brasil, Doutora em Letras (MACKENZIE), Professora nos cursos \\ de Graduação - Secretariado Executivo, Administração, Ciências Contábeis, Ciências Econômicas - e de Pós-Graduação em \\ Assessoria Executiva (FECAP), e-mail: lucianaluciani@yahoo.com.br \\ ${ }^{2}$ Fundação Escola de Comércio Álvares Penteado (FECAP), Brasil, Graduanda em Secretariado Executivo Trilíngue (FECAP), \\ e-mail: beatriz.naves@edu.fecap.br
}

\section{RESUMO}

Dada à crescente demanda de atividades exercidas pelo(a) Secretário(a) Executivo(a), atuante como cogestor de seus assessorados no atual cenário corporativo, é natural que muitos profissionais da área absorvam funções de cunho gerencial, dentre as quais cita-se a gestão de projetos. Para tal, é necessário que o Secretário(a) Executivo(a), além de outras capacidades, desenvolva e mobilize competências intraempreendedoras. Diante desse contexto, a presente pesquisa tem como objetivo verificar quais fatores levam profissionais de secretariado executivo a propor um projeto e, como consequência, tornarem-se responsáveis pela sua gestão na empresa em que atuam. Para contemplar tal estudo, como metodologia, foram empreendidas pesquisas bibliográficas, bem como coleta de dados a partir de entrevistas realizadas com profissionais da área secretarial que idealizaram e geriram projetos em suas organizações. Como resultado, verificou-se que os fatores motivacionais, ou seja, os fatores intrínsecos têm uma maior preponderância em relação aos fatores higiênicos (extrínsecos). Ademais, constatou-se que as competências necessárias à atuação secretarial são compatíveis com o perfil de um gestor de projetos.

Palavras-chave: Secretário(a) Executivo(a). Competências intraempreendedoras. Gestão de projetos.

\begin{abstract}
Given the increasing demand of activities performed by the Executive Secretary, who is working as comanager of your advisors in the corporate setting, it is notorious that many professionals in the area develop managerial functions, which project management can be mentioned. For this purpose, it is necessary that the Executive Secretary, in addition to other capabilities, develop and mobilize intrapreneurial competencies. In this context, this research aims to verify which factors lead secretarial professionals to proposing and managing a project and, as a result, become responsible for management in the company where they work. To behold this research, as methodology, it was applied bibliographic research, as well as data collection from interviews conducted with secretarial professionals who conceived and managed projects in your organizations. As a result, motivational factors (intrinsic factors) have a greater predominance in relation to hygienic factors (extrinsic). Furthermore, the necessary competencies required for the secretarial work are compatible with the profile of a project manager.
\end{abstract}

Keywords: Executive Secretary. Intrapreneurial competencies. Project management. 


\section{INTRODUÇÃO}

Para o exercício de uma profissão, é necessário que um indivíduo adquira e mobilize competências específicas de sua atividade que, de modo geral, são: a) garantidas ao longo da formação acadêmica, em especial, em nível superior; b) determinadas pela respectiva lei de regulamentação, se houver; c) requisitadas pelo mercado de trabalho.

Nesse tripé - formação-regulamentação-mercado -, algumas competências, sejam elas técnicas ou comportamentais, destacam-se e são priorizadas em relação a outras, ou poderão vir a ser desenvolvidas e mobilizadas, a depender do contexto em que o profissional, independentemente do nível hierárquico, está inserido. É o caso, por exemplo, do profissional que idealiza, propõe, elabora e faz a gestão de um ou mais de um projeto para a empresa na qual atua.

Conforme o PMBoK (2017), o gerenciamento de projetos envolve a utilização, aplicação e integração, de modo apropriado, de ferramentas, técnicas, habilidades e conhecimentos para que se alcance todos os requisitos necessários à concretização de um ou mais objetivo pré-definido. Para Gido, Clements e Baker (2018, p. 7), “o processo de gestão de projetos envolve planejar o trabalho e trabalhar no planejamento".

Para o gerenciamento de um projeto, é necessário que esteja à frente indivíduos hábeis em construir e liderar equipes, motivar pessoas e motivar-se, negociar, gerenciar conflitos, tomar decisões, manter bons relacionamentos interpessoais, equilibrar metas, influenciar e responsabilizar-se pela equipe envolvida (RABECHINI JUNIOR, 2008). Tais competências e habilidades vão ao encontro do perfil empreendedor e/ou intraempreendedor indicado por Dornelas (2005).

Partindo-se desses apontamentos e considerando as vivências de profissionais de secretariado executivo que atuaram na idealização, proposição, elaboração e gestão de um projeto para as organizações das quais fazem (ou fizeram) parte, surge a seguinte pergunta: Quais fatores levaram os profissionais de secretariado executivo a propor um projeto e, como consequência, tornarem-se responsáveis pela sua gestão na empresa em que atuam?

Em conjunto com este questionamento que conduz ao objetivo geral, isto é, verificar quais fatores foram preponderantes a Secretários(as) Executivos(as) para a proposição e gestão de um projeto, esta pesquisa busca: a) identificar o papel a ser desenvolvido por um gestor de projetos, a fim de examinar se o perfil profissional do Secretário(a) Executivo(a) vai ao 
encontro dos requisitos necessários; e b) discutir quais competências intraempreendedoras foram essenciais para os profissionais da área secretarial que estiveram à frente da gestão de um projeto.

Para contemplar os objetivos, geral e específicos, foram empreendidas pesquisas bibliográficas, fundamentais à base teórica deste estudo, em especial, no que concerne: à teoria dos dois fatores de Herzberg (CHIAVENATO, 2014; MARQUES, 2016; VECCHIO, 2012; ZWICKER et al., 2018); ao gerenciamento de projetos (IRELAND; CLELAND, 2007; VARGAS et al., 2010; FIGUEIREDO, 2013; PMBoK, 2017; WILLIAMS, 2017; CAVALCANTI et al., 2018; CLEMENTS; BAKER, 2018; DAFT, 2017; FIGUEIREDO; GIDO et al., 2018;) e, ainda, à noção de competências intraempreendedoras com vistas às responsabilidades inerentes aos profissionais da área secretarial na gestão de projetos (DORNELAS, 2005; LE BOTERF, 2007; FUMAGALI, 2008; MAZULO; LIENDO, 2010; NEIVA; D'ELIA, 2014; MARINHO, 2015; TODOROV, 2015; KURATKO, 2016; CAMARGO, 2017; FARAH et al., 2017).

Compreende-se que tal investigação teórica-metodológica acerca do tema competências se faz necessária, pois, ratificando Dornelas (2005) e Rabechini Junior (2008), a proposição de um projeto pode, de modo inicial, ser motivada por fatores extrínsecos e/ou intrínsecos, contudo, subjaz a mobilização de competências para que a gestão seja conduzida formal e adequadamente. Ao discutir tais competências em âmbito secretarial, oportuniza-se a identificação das competências secretariais necessárias à gestão de projetos. Desse modo, esta pesquisa pode vir a colaborar com a gestão organizacional ao demonstrar a capacidade de atuação, em frentes variadas, do(a) Secretário(a) Executivo(a).

Por fim, esclarece-se que este artigo está dividido nas seguintes sessões: referencial teórico; procedimentos metodológicos; apresentação e análise dos resultados; e considerações finais.

\section{REFERENCIAL TEÓRICO}

\subsection{TEORIA DOS DOIS FATORES DE HERZBERG}

Há uma grande quantidade de conceitos para o termo motivação. Todavia, as diversas noções estão relacionadas entre si ou apresentam diferenças mínimas (LOBOS, 1975). Desse 
modo, a fim de buscar uma compreensão norteadora para esta pesquisa, reconhecendo nas palavras de Williams (2017, p. 278), aqui assume-se motivação como sendo “[...] o conjunto de forças que inicia, direciona e faz com que as pessoas persistam em seus esforços para atingir um objetivo".

Como complemento, para compreender o conceito de motivação, ou melhor, mais especificamente, a noção de motivação em âmbito do trabalho, levando em consideração o objetivo central desta pesquisa, recorreu-se a Griffin e Moorhead (2015). Esses autores declaram que as forças que dirigem o comportamento de um indivíduo podem ser internas ou externas e impactam diretamente na produtividade dos profissionais. Além disso, os mesmos autores esclarecem que garantir e promover motivação, de modo geral, é um dos focos dos gestores (ou deveria ser), uma vez que estes, ao canalizarem as motivações diversas, caminham em direção aos objetivos da organização.

Em desdobramento a tais entendimentos, é possível afirmar que há três orientações elementares que sustentam o conceito aqui mostrado: forças (ou fatores), esforços e objetivo(s), sobre os quais a maior parte das teorias acerca da noção de motivação, resguardados os diferentes aportes teóricos, discorrem a respeito.

Dentre essas teorias motivacionais aplicáveis às situações de trabalho, embora não de forma exclusiva, destacam-se os estudos de Douglas McGregor (1906-1964), Abraham Maslow (1908-1970) e Frederick Herzberg (1923-2000). Em comum, os três autores defendem que a motivação, a partir de uma base de "conjunto de forças", conduz o comportamento social humano nas organizações.

Como não pretendia dar um caráter valorativo às suas teorias, Douglas McGregor, psicólogo social, professor e economista, simplesmente denominou as suas contribuições à área das relações humanas de Teoria X e Teoria Y. Para McGregor, o modo como o trabalho é percebido pode ser diferente entre os indivíduos: a Teoria $\mathrm{X}$ propõe que o trabalho é desagradável para a maioria das pessoas; em contrapartida, a Teoria Y defende que o trabalho pode ser tão natural como o lazer, se as condições forem favoráveis. Tais percepções podem provocar diferentes impactos no ambiente organizacional, conforme afirma Marques (2016) ao discorrer sobre essas teorias.

Entre os adeptos da Teoria X, segundo explica Freitas (2009), não há ambição. Os indivíduos evitam riscos e responsabilidades, preferindo ser dirigidos. Por outro lado, as pessoas que se identificam com a Teoria $\mathrm{Y}$ “[...] são esforçadas, buscam e assumem 
responsabilidades, têm iniciativa, podem ser autônomas, são criativas e competentes quando possuem condições para realizar o trabalho" (MARQUES, 2016, p. 44). Ao que acrescenta Daft (2017, p. 77): "Segundo a Teoria Y, as empresas podem aproveitar a imaginação e o intelecto de todos os funcionários, que exercerão o autodirecionamento e o autocontrole para contribuir com os objetivos organizacionais quando a oportunidade lhes for apresentada".

Portanto, com base nas teorias de McGregor, compreender como o indivíduo percebe o trabalho e de que modo esse impacta em seu comportamento e gera motivação é fundamental para a gestão dos recursos humanos de uma empresa. Com efeito, é preciso que as organizações desenvolvam ambientes e processos de trabalho distintos, a fim de engajar a todos que delas fazem parte.

Para Abraham Maslow, a motivação é baseada na classificação hierárquica das necessidades básicas do ser humano. A fim de elucidar sua teoria, a qual convencionou-se denominar "Hierarquia de necessidades de Maslow", o psicólogo norte-americano distribuiu cinco necessidades humanas em uma pirâmide, sendo que as necessidades mais essenciais estão alocadas na base e são seguidas pelas demais em direção ao topo (LOBOS, 1975).

Essa pirâmide de Maslow divide-se entre as necessidades de sobrevivência ou deficiência - necessidades fisiológica, de segurança e afetiva -, e necessidades de crescimento - necessidade de estima e autorrealização, nessa respectiva ordem de baixo para cima.

Conforme explica Lobos (1975, p. 19):

Maslow indicou que o menor nível insatisfeito nesta hierarquia monopolizará a consciência do indivíduo, impulsionando-o "a organizar o recrutamento das várias capacidades de seu organismo". Uma vez satisfeita, essa necessidade é esquecida por completo, ainda que só para ser substituída por outras necessidades de nível superior.

Daft (2017), por seu turno, esclarece que as necessidades fisiológicas estão relacionadas à alimentação, à água e ao oxigênio; as necessidades de segurança aos ambientes físico e emocional - ambos seguros e livres de ameaças; as necessidades afetivas concernem aos sentimentos de aceitação, amizade e pertencimento a um (ou mais) grupo; as necessidades de estima estão ligadas ao desejo de autoimagem positiva, reconhecimento e apreciação; por fim, as necessidades de autorrealização referem-se ao desenvolvimento do pleno potencial do indivíduo.

Segundo Griffin e Moorhead (2015), no ambiente organizacional, essas necessidades são descritas da seguinte maneira: a) necessidades fisiológicas, relacionadas às condições de trabalho, como ventilação e instalações sanitárias; b) necessidades de segurança, referente à 
continuidade do cargo exercido, aos sistemas de reclamações e de seguro e aposentadoria; c) necessidades afetivas, satisfeitas pelos laços familiares e grupos de trabalho que ocorrem dentro ou fora da organização; d) necessidades de estima, concernentes a cargo, espaço físico, aumento salarial e prêmios; d) necessidades de autorrealização, ligadas à realização plena.

A terceira teoria - teoria motivacional de Frederick Herzberg - fundamenta a presente pesquisa e, por essa razão, tem um tratamento mais extenso em relação aos estudos de McGregor e Maslow, anteriormente apresentados, como se constata na sequência.

Conhecida pelo nome de "Teoria dos dois fatores", a abordagem de Herzberg “[...] constitui uma das visões mais amplamente difundidas e influentes da motivação no trabalho" (VECCHIO, 2012, p. 77), e discrimina os elementos que moldam o comportamento organizacional em: fatores extrínsecos e fatores intrínsecos. Esclarece-se que esses fatores foram originariamente identificados através de uma seleção de incidentes críticos obtidos após uma série de entrevistas efetuadas com contadores e engenheiros em Pittsburgh (Estados Unidos), nos anos de 1950-1960. Com base em Lobos (1975, p. 19), "Estes incidentes críticos referiam-se a situações de trabalho nas quais as pessoas entrevistadas informavam haver-se sentido particularmente bem ou mal".

Chiavenato (2014), ao explicar a teoria herzbergiana, esclarece que os fatores extrínsecos, também denominados de fatores higiênicos, são aqueles administrados e decididos pela empresa. Por sua vez, os intrínsecos ou motivacionais (outra denominação dada para esses fatores) são aqueles gerados pelo indivíduo e, portanto, estão sob o controle do profissional.

Para Zwicker et al. (2018), os fatores higiênicos não são muito eficazes a médio e longo prazo. Isso ocorre, pois, em geral, as organizações motivam seus colaboradores com prêmios, aumentos salariais, infraestrutura, entre outras ações. Esses incentivos não são sustentáveis, duram pouco, pois são decididos e geridos pelos empregadores.

Os fatores motivacionais estão relacionados à satisfação que a função e as atividades desempenhadas geram aos profissionais a partir do cargo ocupado. São de ordem individual, pois estão sob o controle de cada um. Os fatores motivacionais envolvem sentimentos de crescimento individual, situações de reconhecimento profissional e autorrealização, autonomia, conquistas, significado do trabalho e oportunidades para avanços na carreira e no crescimento pessoal (CHIAVENATO, 2014; ZWICKER et al., 2018).

Em síntese aos estudos de Chiavenato (2014) e Zwicker et al. (2018) acerca da teoria de Herzberg, propõe-se o Quadro 1 comparativo entre os fatores:

Revista Expectativa, Toledo/PR, v.20, n. 4, p. 35-60, out./dez., 2021. 
Quadro 1 - Teoria dos dois fatores de Herzberg

\begin{tabular}{|l|ll|}
\hline \multicolumn{1}{|c|}{ Fatores higiênicos } & \multicolumn{1}{c|}{ Fatores motivacionais } \\
\hline \multicolumn{1}{|c|}{ Esforço organizacional } & \multicolumn{1}{c|}{ Esforço individual } \\
\hline$>$ Condições de trabalho & $>$ Trabalho em si \\
$>$ Sdministração e política da empresa & $>$ Responsabilidade \\
$>$ Benefícios e incentivos & $>$ Progresso profissional \\
$>$ Relacionamento interpessoal com superiores, & $>$ Reconhecimento \\
\hline
\end{tabular}

Fonte: Elaborado pelas pesquisadoras (2020).

Marques (2016) declara que para Herzberg os fatores motivacionais devem ser o foco das organizações, pois podem gerar um ambiente propício à motivação própria dos funcionários. Vecchio $(2012$, p. 78) também já apontava na mesma direção ao evidenciar que "[...] melhorar as condições físicas do trabalho pode ajudar a reduzir a insatisfação dos colaboradores, porém, não oferecerá incentivo suficiente para que a maior parte deles se empenhe por um desenvolvimento excelente".

Nessa perspectiva, constata-se, portanto, que os fatores higiênicos, ao serem gerados pela empresa, produzem um sentimento de satisfação de pouca durabilidade. Em outras palavras, esses fatores são vistos como motivadores de resultados, isto é, estão a serviço da empresa e visam, sobretudo, aumento e melhoria da produção. Por outro lado, os fatores motivacionais geram impacto e benefícios de longo prazo. Isso decorre, uma vez que, sendo gerados pelos próprios profissionais, resultam em benefícios mais sustentáveis e, por conseguinte, têm menos probabilidade de acabar, podendo conduzir os trabalhadores ao protagonismo de, por exemplo, propor e gerenciar um (ou mais) projeto na organização em que atuam.

\subsection{A GESTÃO E O GESTOR DE PROJETOS}

Chiavenato (2014) define projetos como criações únicas, com datas definidas para início e fim, de um produto ou serviço. Ainda segundo o mesmo autor, os projetos não fazem parte das ações operacionais comuns que estão presentes dentro de uma organização, porém podem ser implementados em todo e qualquer nível organizacional. Figueiredo e Figueiredo (2013) esclarecem que os projetos, a partir de um conjunto interligado de tarefas, almejam atingir um objetivo previamente traçado. Ireland e Cleland (2007) citam que os projetos são elementos 
executores de mudanças, os quais oportunizam a sobrevivência e o crescimento das organizações.

Diante de tais conceituações, é possível inferir que todo projeto demanda uma gestão para que o desenvolvimento e a finalização correspondam ao que foi planejado. Segundo Gido, Clements e Baker (2018, p. 12), "Gestão de projetos significa planejar, organizar, coordenar, liderar e controlar recursos para concretizar o objetivo do projeto". Vargas (2003) esclarece que o gerenciamento de projetos não é revolucionário, mas sim um processo estruturado e lógico. Ainda de acordo com Vargas (2003), gerenciar projetos envolve utilizar ferramentas gerenciais que implicam desenvolvimento de habilidades e conhecimentos individuais, para que se possa controlar, de modo predeterminado, prazos, custos e qualidade. Nesse sentido, conforme orienta Williams (2017, p. 3), é necessário “[...] criar um ambiente em que as pessoas sejam capazes de fazer o trabalho de maneira eficiente e eficaz".

Cumpre salientar que a gestão de projetos não é um empreendimento oriundo das recentes teorias organizacionais. Ao analisar os grandes feitos da humanidade, constata-se que desde a Antiguidade (4.000 a.C. a 476 d.C.), com a construção das pirâmides do Egito, da Muralha da China, do Coliseu e do Pathernon, por exemplo, o gerenciamento de projetos se fez e está presente nas mais diversas civilizações (VALLE et al., 2010). No entanto, as pesquisas concernentes à ciência de gerenciamento de projetos principiaram no início do século XIX, concomitantemente ao crescimento do sistema fabril (DAFT, 2017).

Valle et al. (2010) citam que os primeiros estudiosos da área de gestão de projetos foram Frederick Taylor (1856-1915) com a proposta de isolamento das partes elementares de um projeto ou serviço, e Henry Gantt (1861-1919), sócio de Taylor, com a idealização da ordem das operações exercidas, gerando, a partir desse princípio, os gráficos de Gantt, utilizados até hoje em projetos que têm por necessidade gerenciar equipes e atividades nas áreas de engenharia, produção e tecnologia da informação, por exemplo. Ainda de acordo com os mesmos autores, outros feitos são provenientes das pesquisas científicas relacionadas ao gerenciamento de projetos: o lançamento do satélite Sputnik em 1950 pela União Soviética; a popularização do termo de gerenciamento por objetivos em 1954 por Peter Drucker (19692005); a citação do termo de gerente de projetos em 1959 por John Lewis Gaddis (1941-); a publicação de 35 padrões de gestão e controle de projetos em 1969 pelo departamento de defesa norte-americano.

Revista Expectativa, Toledo/PR, v.20, n. 4, p. 35-60, out./dez., 2021. 
Conforme pode ser constatado nesse breve retrospecto histórico, o gerenciamento de projetos demanda evolução tecnológica, criação e, muitas vezes, inovação com elevação da qualidade e diminuição de tempo e recursos, conduzindo, desse modo, os envolvidos a contextos de alta performance e competitividade. Porém, de acordo com Vargas (2003), o gerenciamento de projetos não é restrito a projetos gigantescos, como os que foram aqui apresentados, e pode ser, portanto, aplicado para a gestão de empreendimentos de diferentes níveis de complexidade e orçamento em âmbito organizacional, por exemplo.

Porém, para qualquer empreendimento, a gestão de projetos deve seguir uma linha criteriosa de processos. O PMBoK (2017) enumera cinco fases de processos, conforme se apresenta na Figura 1:

Figura 1 - Fases processuais para a gestão de projetos

\begin{tabular}{|c|c|c|c|c|}
\hline $\begin{array}{l}\text { 1) iniciação } \\
\text { • definição de um } \\
\text { novo projeto ou } \\
\text { uma nova fase } \\
\text { de algo já } \\
\text { existente }\end{array}$ & $\begin{array}{l}\text { 2) planejamento } \\
\text { • delimitação de } \\
\text { todos os } \\
\text { objetivos e } \\
\text { ações }\end{array}$ & $\begin{array}{l}\text { 3) execução } \\
\text { • etapa para } \\
\text { concluir o que } \\
\text { foi definido }\end{array}$ & $\begin{array}{l}\text { 4) } \\
\text { monitoramento } \\
\text { e controle } \\
\text { - desempenho do } \\
\text { trabalho, isto é, } \\
\text { como ele está } \\
\text { sendo } \\
\text { executado }\end{array}$ & $\begin{array}{l}\text { 5) } \\
\text { encerramento } \\
\text { • conclusão } \\
\text { oficial do } \\
\text { projeto }\end{array}$ \\
\hline
\end{tabular}

Fonte: Adaptado de PMBoK (2017).

Gido et al. (2018), ao também discutirem os processos necessários para a gestão de projetos, esclarecem que na iniciação, isto é, no primeiro passo do ciclo de vida de um projeto, é identificado um problema ou uma oportunidade para a empresa, sendo que, nessa fase, é necessário ser desenvolvido um documento denominado termo de abertura do projeto. Após a iniciação, a fase do planejamento tem por objetivo criar um roteiro que irá determinar exatamente o que será feito, como será feito, quem o fará, qual será a duração, o orçamento e os riscos do projeto. A terceira fase, ou seja, a execução diz respeito à realização e à conclusão do projeto. A etapa subsequente, monitoramento e controle, objetiva minimizar os impactos negativos que poderão ocorrer durante a fase de execução. Por fim, a fase de encerramento compreende o conjunto de ações que finalizarão o projeto - como por exemplo, fazer os 
pagamentos finais, avaliar o que foi aprendido com os erros e os acertos -, e arquivar toda a documentação gerada e desenvolvida ao longo do projeto.

Obviamente, toda gestão de projetos requer um gestor. Contudo, nem todo profissional tem perfil para gerir um projeto. Conforme explicam Cavalcanti, Farah e Marcondes (2018, p. 48), para estar à frente dessa atividade, é necessário que o gestor tenha nível de conhecimento acima da média, bem como nível educacional elevado, pois o gerenciamento de projetos demanda profissionais que saibam “[...] interpretar textos e situações, ler os sinais dos acontecimentos atuais, bem como as consequências e as tendências".

Ao discorrer sobre o perfil que todo gestor de projetos deve apresentar, o PMBoK (2017) elenca três habilidades-chave: 1) capacidade de gerenciamento de projetos técnicos; 2) liderança; 3) capacidade de gerenciamento estratégico e de negócios. A primeira habilidade está relacionada ao conhecimento das especificidades técnicas próprias do projeto em questão. A segunda, liderança, está relacionada à assertividade que o gestor precisa ter para orientar a equipe que irá ajudá-lo na execução das atividades necessárias e descritas no planejamento. A última habilidade diz respeito às ações do gestor para melhor condução do projeto, a fim de alcançar os resultados previstos.

Reconhece-se que além dos perfis apresentados por Cavalcanti et al. (2018) e pelo PMBoK (2017), outras competências são necessárias a um gestor de projetos. Tais competências serão discutidas na próxima seção, focalizando os profissionais que, enquanto funcionários de uma empresa, qual seja o setor, contribuem com os resultados organizacionais ao gerirem projetos. Cumpre esclarecer, ainda, que tal discussão buscará aproximar as competências intraempreendedoras necessárias para se gerenciar projetos àquelas comumente requisitadas a Secretários(as) Executivos(as) para o desenvolvimento de suas atribuições em uma companhia, e que podem levá-los(as) à gestão de um (ou mais) projetos.

\subsection{COMPETÊNCIAS INTRAEMPREENDEDORAS DO PROFISSIONAL DE SECRETARIADO EXECUTIVO COM VISTAS AO GERENCIAMENTO DE PROJETOS}

Assim como a palavra motivação, tópico de discussão na primeira seção deste estudo, o termo empreendedorismo segue várias correntes de pensamentos, podendo ser concebido de acordo com as perspectivas individuais e/ou organizacionais, como se apresenta na sequência. 
Farah, Cavalcanti e Marcondes (2017, p. 5) definem empreendedorismo como: “A ação de um indivíduo para criar um novo empreendimento, incentivado por uma necessidade pessoal, pela interação com o meio que se relaciona ou pela descoberta de uma oportunidade de negócio”. Kuratko (2016), em consonância com os autores citados, define empreendedorismo como tudo aquilo que envolve e mobiliza ações de um indivíduo no âmbito de negócios para agir de forma inovadora, buscando e apresentando soluções. Dornelas (2005, p. 29), por sua vez, conceitua empreendedorismo como sendo "o envolvimento de pessoas e processos que, em conjunto, levam à transformação de ideias em oportunidades. E a perfeita implementação destas oportunidades leva à criação de negócios de sucesso".

À frente de ações empreendedoras estão, certamente, indivíduos empreendedores, isto é, pessoas capazes de detectar uma oportunidade, criar um negócio e capitalizar sobre ela, ao assumir riscos calculados (DORNELAS, 2005) e reconhecendo, muitas vezes, essa oportunidade em meio ao caos, às contradições e confusões de um determinado segmento (KURATKO, 2016).

Ao citar o economista e cientista político Joseph Schumpeter (1833-1950), Dornelas $(2005,39)$ explica que "[...] o empreendedor é mais conhecido como aquele que cria novos negócios, mas pode também inovar dentro de negócios já existentes; ou seja, é possível ser empreendedor dentro de empresas já constituídas”. Nessa última perspectiva, compreende-se o profissional como um agente de mudanças que contribui com a estrutura organizacional da qual faz parte, agregando valor ao(s) negócio(s) da empresa a partir do seu comportamento empreendedor.

As ações empreendedoras e internas são denominadas, entre alguns estudiosos da área, de intraempreendedorismo, como uma forma de abreviar o termo empreendedorismo intracorporativo (FUMAGALI, 2008).

O intraempreendedorismo, conforme Kuratko (2016), pode ser dividido em: 1) empreendedorismo corporativo, ou seja, quando há a intenção de criar novos negócios; e 2) empreendimento estratégico, isto é, quando há a intenção de obter vantagem competitiva sem resultar em novos negócios. Tanto para o empreendedorismo corporativo quanto para o estratégico, é necessário que os profissionais apresentem determinadas competências intraempreendedoras.

Dada as diversas acepções que a palavra competência adquire nos mais variados campos do saber, cumpre elucidar que, para os fins desta pesquisa, compreende-se por competência o

Revista Expectativa, Toledo/PR, v.20, n. 4, p. 35-60, out./dez., 2021. 
conjunto de conhecimentos, habilidades e atitudes que um indivíduo desenvolve (ou é levado a desenvolver) ao longo de sua trajetória pessoal e/ou profissional. Esse pilar da competência conhecimentos, habilidades e atitudes - é referenciado, em especial na área dos estudos de contexto laboral, pelo acrônimo C.H.A. (FLEURY; FLEURY, 2001).

Segundo Marinho (2015), o conhecimento concerne a todos os aprendizados adquiridos ao longo da vida, a habilidade trata da mobilização desses aprendizados para a prática e a atitude diz respeito aos comportamentos que regem as ações individuais. Sobre essa questão que considera o caráter individual da atitude, Camargo (2017) declara que a competência pode ser considerada como uma característica individual, uma vez que se trata de um estoque de recursos adquirido pelo próprio indivíduo.

No entanto, para que um profissional seja considerado competente em determinada área, é necessário considerar o que explica Le Boterf (2007, p. 48):

\footnotetext{
O profissional não é aquele que possui conhecimentos ou habilidades, mas aquele que sabe mobilizá-los em um contexto profissional. [...] Possuir saberes ou capacidades não significa ser um profissional competente. Pode-se conhecer as técnicas ou regras de gestão contábil e não saber aplicá-las no momento oportuno. Pode-se conhecer direito comercial e redigir mal os contratos. A competência é sempre "competência para" (LE BOTERF, 2007, p. 48).
}

De acordo com Dornelas (2005), as "competências para" empreender e, desse modo, assume-se aqui também, intraempreender, dividem-se em competências técnicas, gerenciais e pessoais. As competências técnicas estão ligadas à boa oratória, organização, liderança e gestão de pessoas. Já as competências gerencias relacionam-se à capacidade de criar e gerir novos negócios. Por fim, as competências pessoais concernem para disciplina, assunção de riscos e inovação.

Ao apresentar tais competências e, portanto, um perfil intraempreendedor, é natural que os profissionais possam vir a ser responsáveis por propor e gerir projetos para as organizações das quais fazem parte. Dentre este rol de profissionais, podem ser integrados os(as) Secretários(as) Executivos(as). Para Mazulo e Liendo (2010), o profissional da área secretarial deve mobilizar conhecimentos técnicos e operacionais, bem como habilidade pessoal para a boa gestão de pessoas e serviços, a fim de entregar os resultados esperados e inerentes as suas atribuições. Ainda conforme as autoras, o profissional de secretariado, ainda que, em geral, não tenha nível hierárquico gerencial, possui funções gerenciais, sendo essas reconhecidas como condição imprescindível para o exercício da profissão.

Revista Expectativa, Toledo/PR, v.20, n. 4, p. 35-60, out./dez., 2021. 
Também nessa discussão acerca do perfil e das competências do Secretariado Executivo, Neiva e D'Elia (2014) apontam para o fato de que os profissionais precisam ser aptos a perceber o ambiente, as pessoas, os códigos ditos e aqueles implícitos, assim como ter equilíbrio emocional, visão holística da empresa e criatividade para personalizar seu atendimento a clientes internos e externos. Marinho (2015, p. 35) afirma que a competência do(a) Secretário(a) Executivo(a) não pode ser avaliada somente pela capacidade em lidar com papéis e objetos materiais, mas também pela habilidade em lidar com pessoas.

Os resultados de uma pesquisa empreendida por Todorov (2015) apontam que os profissionais de Secretariado Executivo dispõem de competências fundamentais para contribuir com a gestão de projetos nas organizações, segundo a percepção de gestores de projetos. Dentre as principais competências elencadas no estudo, estão: capacidade de articulação, visão generalista da organização, domínio dos recursos de expressão e de comunicação e gerenciamento de informações.

Como pode ser verificado, as descrições apresentadas por pesquisadores da área não somente convergem com as competências intraempreendedoras abordadas por Dornelas (2005), como também ampliam a descrição sumária da Classificação Brasileira de Ocupações (CBO) (2010) acerca dos(as) Secretários(as) Executivos(as), cujo texto define esses profissionais como aqueles que:

\begin{abstract}
Assessoram os executivos no desempenho de suas funções, atendendo pessoas (cliente externo e interno), gerenciando informações, elaboram documentos, controlam correspondência física e eletrônica, prestam serviços em idioma estrangeiro, organizam eventos e viagens, supervisionam equipes de trabalho, gerem suprimentos, arquivam documentos físicos e eletrônicos auxiliando na execução de suas tarefas administrativas e em reuniões (CBO, 2010).
\end{abstract}

Ao atuarem ao lado dos níveis decisórios das organizações e levando em consideração todas as competências que devem ser desenvolvidas e mobilizadas pelos profissionais da área secretarial, é comum que o(a) Secretário(a) Executivo(a) questione processos de trabalho e formas de trabalho, busque melhorias para os processos já existentes ou, ainda, desenvolva novas estruturas de poder e liderança nas organizações (MARINHO, 2014). Reconhece-se, nesse escopo de atuação, um perfil intraempreendedor, conforme discutem Higa, Lima e Santos (2017, p. 24):

A atuação do profissional evolui e permanece evoluindo, o aperfeiçoamento de características empreendedoras contribui para o desenvolvimento do intraempreendedorismo secretarial. Com o desenvolvimento dessas características o

Revista Expectativa, Toledo/PR, v.20, n. 4, p. 35-60, out./dez., 2021. 
profissional teve a ampliação da área de atuação profissional, uma vez que já fazem parte da sua rotina as atividades como: planejar, administrar e gerenciar (HIGA; LIMA; SANTOS, 2017, p. 24).

Nesse sentido, entendendo que o(a) Secretário(a) Executivo(a) exerce funções gerenciais, cujas atividades de planejamento, administração e gerenciamento estão hoje incutidas em sua rotina, assume-se que os profissionais da área secretarial podem vir a ser gestores de projetos. Para tanto, compreende-se que tal responsabilidade é conduzida pelos fatores higiênicos (ou extrínsecos) e, sobretudo, pelos fatores motivacionais (intrínsecos). Ademais, faz-se necessário o desenvolvimento e a mobilização de competências intraempreendedoras, como será discutido e apresentado mais adiante nesta pesquisa por meio do levantamento empreendido com profissionais da área secretarial.

\section{PROCEDIMENTOS METODOLÓGICOS}

O presente estudo, de natureza aplicada e com fins exploratórios, foi construído por meio de uma abordagem qualitativa. Além do levantamento bibliográfico apresentado na seção anterior, recorreu à técnica de coleta de informações, a fim de buscar responder ao problema de pesquisa: Quais fatores levaram os profissionais de secretariado executivo a propor um projeto e, como consequência, tornarem-se responsáveis pela sua gestão na empresa em que atuam?

Para tanto, foram entrevistadas três profissionais da área secretarial (todas três do gênero feminino), com atuação no setor privado, em São Paulo (capital). As três participantes foram convidadas a contribuir com este estudo, uma vez que todas propuseram um ou mais de um projeto para as organizações que trabalham na atualidade ou já trabalharam. Além disso, cumpre explicar que as participantes são profissionais reconhecidas no meio do secretariado executivo pelos seus respectivos protagonismos na gestão de projetos, sendo estes, os projetos, compartilhados em eventos da categoria por mais de uma ocasião. Foram, por meio desses eventos, que as pesquisadoras puderam conhecer tais projetos e secretárias. A primeira abordagem às participantes foi feita por mensagem, através da rede social LinkedIn, cujas três são inscritas e já estabeleciam conexões com as pesquisadoras.

As entrevistas foram feitas individualmente, sendo que duas ocorreram em dezembro de 2020 e uma em fevereiro de 2021, conforme disponibilidade e consentimento das entrevistadas. Esclarece-se, ainda, que as entrevistas foram realizadas na modalidade on-line

Revista Expectativa, Toledo/PR, v.20, n. 4, p. 35-60, out./dez., 2021. 
pelas seguintes plataformas de videoconferência: Zoom para a primeira entrevista e Microsoft Teams para as outras duas entrevistas.

A escolha dessa técnica de coleta de informações deu-se por compreender que a entrevista, sendo uma conversa realizada frente a frente, possibilita a obtenção das informações necessárias para responder a uma investigação ou um problema social, conforme explicam Marconi e Lakatos (2003). Recorrendo a Laville e Dionne (1999), a entrevista tem menos chances de comprometer um projeto quando comparada ao questionário. Isso se dá porque a entrevista aumenta a taxa de resposta, ao permitir que as perguntas sejam exploradas fortemente pelas partes, orientando os entrevistados ao objetivo do pesquisador.

De caráter subjetivo, buscando dados qualitativos baseados nas opiniões das entrevistadas, foram conduzidas entrevistas semiestruturadas, ou seja, foi utilizado um roteiro durante o processo de coleta de informações. O roteiro de entrevista desta pesquisa foi composto por treze questões divididas em três tópicos: motivação, projeto e competências. Antes de adentrar a esses tópicos, procurou-se, por meio de seis questões, conhecer o perfil acadêmico e profissional de cada entrevistada. Todos os questionamentos buscaram direcionar as entrevistadas a discursarem com vistas a responder o problema de pesquisa apresentado neste estudo. Conforme explica Flick (2013, p. 115), nas “[...] entrevistas semiestruturadas são preparadas várias perguntas que cobrem o escopo pretendido da entrevista", ao que complementam Martins e Theóphilo (2016, p. 89), “[...] com liberdade de serem acrescentadas novas questões pelo entrevistador".

Após a conclusão da última entrevista em fevereiro de 2021, todos os dados coletados foram transcritos para garantir uma melhor fidelidade às respostas obtidas e, por conseguinte, análise assertiva das informações. Cumpre salientar que todas as etapas - entrevista, transcrição e análise -, para os pretendidos fins deste estudo, foram autorizadas via Termo de Participação, devidamente assinado pelas entrevistadas, sob o compromisso de manter o sigilo da identidade das participantes e das respectivas organizações. Para tanto, na próxima seção, em que se promove a análise e discussão dos resultados, as entrevistadas serão identificadas por E1, E2 e E3, de acordo com a ordem cronológica em que foi feita cada entrevista.

Para análise dos dados coletados, optou-se pela técnica Análise de Conteúdo (AC). Segundo Bardin (2011), a AC pode ser compreendida como um conjunto de técnicas de análises das comunicações que possibilitam fazer inferências de conhecimentos acerca das condições

Revista Expectativa, Toledo/PR, v.20, n. 4, p. 35-60, out./dez., 2021. 
de produção e/ou recepção, a partir da codificação de uma unidade de registro (palavra, tema, objeto ou referente, personagem e acontecimento).

Salienta-se que esta pesquisa fez uma análise temática para estudar as motivações de opiniões, atitudes, valores e crenças das entrevistadas. Optou-se por essa unidade de registro, uma vez que por meio do tema é possibilitado aos pesquisadores “[...] descobrir os "núcleos de sentido' que compõem a comunicação e cuja presença, ou frequência de aparição podem significar alguma coisa para o objetivo analítico escolhido" (BARDIN, 2011, 105).

A partir da AC, as respostas foram comparadas entre si e examinadas à luz do referencial teórico. Recorrendo-se novamente a Flick (2013), evidencia-se que o levantamento de dados em conjunto com a pesquisa bibliográfica possibilita um enriquecimento e destaque das informações, como se propõe a seguir.

\section{APRESENTAÇÃO E ANÁLISE DOS RESULTADOS}

\subsection{PERFIL DAS ENTREVISTADAS}

A primeira parte da entrevista buscou identificar o perfil formativo e profissional das entrevistadas. Desse modo, as três participantes foram questionadas sobre suas formações acadêmicas, o atual cargo profissional, o cargo exercido na ocasião da proposição e do desenvolvimento do projeto e, por fim, tempo de atuação na área secretarial.

E1 esclareceu que possui graduação em Administração de Empresas, com ênfase em Hotelaria, e que participou de diversos cursos que contribuíram para o seu desenvolvimento profissional. A entrevistada informou que, atualmente, é Assistente Executiva Sênior. Relatou que trabalhava em regime temporário na empresa em que propôs e desenvolveu o projeto, sendo, ao final do contrato, efetivada. E1 esclareceu, ainda, que possui nove anos de experiência na área secretarial.

A segunda entrevistada (E2) informou ser graduada em Automação de Escritórios e Secretariado e pós-graduada em Assessoria Executiva. Na atualidade, ocupa o cargo de Secretária Executiva Trilíngue Sênior, sendo este o mesmo cargo exercido na ocasião em que propôs e geriu o projeto. Relatou que atua no secretariado há 21 anos - sua única área de atuação profissional até o momento da entrevista concedida.

Revista Expectativa, Toledo/PR, v.20, n. 4, p. 35-60, out./dez., 2021. 
E3 esclareceu ser graduada em Secretariado Executivo Bilíngue com pós-graduação em Tradução e Interpretação (Inglês/Português). Atualmente é Secretária Executiva Bilíngue e, assim como E2, este cargo é o mesmo exercido no momento da proposição e gestão do projeto. Informou que está na área secretarial há 19 anos.

\subsection{FATORES HIGIÊNICOS, FATORES MOTIVACIONAIS E MOTIVAÇÃO NA PERCEPÇÃO DAS ENTREVISTADAS}

Com a finalidade de obter informações acerca do ambiente organizacional, cujo projeto foi proposto pelas secretárias, dos fatores higiênicos e motivacionais que as levaram a propor o projeto e como definem o termo motivação, as entrevistadas foram direcionadas a responder quatro questões.

A primeira questão solicitou que as entrevistadas descrevessem o ambiente organizacional da empresa que aprovou o projeto proposto por cada uma. E1 informou que o ambiente propiciava o diálogo e, por essa razão, pôde apresentar a ideia do projeto ao seu gestor. E2 disse que a cultura organizacional era rígida e formal, mas que os gestores eram acolhedores e respeitavam a profissão Secretário Executivo. E3, por sua vez, esclareceu que o ambiente organizacional era incentivador, uma vez que os gestores encorajavam os funcionários a intraempreender.

Na sequência, perguntou-se às entrevistadas se a empresa era adepta a novas ideias e/ou projetos. E1 informou que mesmo trabalhando em uma empresa que seguia uma cultura burocrática, os gestores eram acessíveis à proposição de novas ideias e/ou projetos. Devido a esse perfil organizacional, E1 informou que obteve permissão do seu gestor para que o projeto, por ela proposto, fosse desenvolvido. E2 pontuou que, embora a cultura organizacional fosse rígida, como descrito anteriormente, a empresa era adepta a novos projetos e encorajava seus funcionários a propô-los. Desse modo, E2 encontrou abertura e incentivo para o desenvolvimento do seu projeto na organização. E3 esclareceu que a empresa se mostrava disposta a ouvir as ideias dos seus funcionários, estimulando-os, inclusive, a apresentar novas ações. Tal ambiente propiciou a E3 levar seu projeto adiante.

Como terceira pergunta, foi solicitado que as entrevistadas informassem qual nível motivacional se sobressaiu para a proposição e o desenvolvimento do projeto, se a motivação pessoal ou organizacional. Em outras palavras, se foram motivadas pelos fatores higiênicos

Revista Expectativa, Toledo/PR, v.20, n. 4, p. 35-60, out./dez., 2021. 
(extrínsecos) ou motivacionais (intrínsecos) respectivamente. As respostas das entrevistadas foram muito próximas. E1 explicou que foi um conjunto entre motivações pessoais e organizacionais. E2 declarou que a motivação pessoal se sobressaiu, mas que o reconhecimento profissional foi também importante. E3 expôs que sentir paixão pelo que faz e encontrar oportunidade para novas realizações são fatores que a motivam.

A partir das respostas, é possível constatar que, para as três entrevistadas, tanto os fatores higiênicos como os motivacionais, conforme fundamentos da teoria herzbergiana (VECCHIO, 2012; CHIAVENATO, 2014; MARQUES, 2016; ZWICKER et al., 2018), foram determinantes para suas iniciativas e posteriores ações. No entanto, no decorrer das entrevistas, todas evidenciaram que os fatores motivacionais tiveram maior relevância em detrimento aos higiênicos. Conforme apontado por Marques (2016) e Vecchio (2012), os fatores motivacionais - ligados ao trabalho em si, à responsabilidade, à realização pessoal, ao progresso profissional e ao reconhecimento -, geram impactos benéficos para os profissionais e para a empresa, uma vez que profissionais motivados se tornam intraempreendedores, beneficiando a organização em que atuam.

Para encerrar esse segundo bloco de perguntas, foi solicitado às entrevistadas que definissem o termo motivação. E1 descreveu que motivação diz respeito ao sentimento que conduz um indivíduo ao objetivo final, mas a intensidade da motivação pode variar no decurso de um projeto. E2 definiu motivação como uma qualidade que permite as pessoas serem diferentes e fazer a diferença. E3, por fim, esclareceu que o significado de motivação está atrelado aos valores cristãos que segue e guiam sua conduta pessoal e profissional.

Todas as entrevistadas, resguardadas as particularidades de cada percepção, vão ao encontro do que propõe Griffin e Moorhead (2015) acerca do conceito de motivação, uma vez que as três secretárias evidenciaram o quão relevante são as forças internas e externas para um desempenho profissional com vistas a resultados positivos para si e para a empresa.

\subsection{TRÊS PROJETOS SOB A PROPOSIÇÃO E GESTÃO SECRETARIAL}

Essa parte da entrevista foi concentrada em perguntas relativas aos projetos que cada uma das entrevistadas propôs e geriu, objetivando ampliar o conhecimento sobre cada um deles para este estudo. Para tanto, cada participante foi questionada sobre: o ano em que o projeto foi proposto e desenvolvido; o que as levaram a propor o projeto (problema e/ou oportunidade); o

Revista Expectativa, Toledo/PR, v.20, n. 4, p. 35-60, out./dez., 2021. 
objetivo do projeto; as fases de desenvolvimento do projeto; os resultados do projeto; e se o projeto se tornou um processo, destacando o maior desafio encontrado e como foi superado.

Para melhor entendimento e, ainda, comparação dos resultados, as respostas foram organizadas no Quadro 2. As declarações que correspondem ao maior desafio encontrado e como foi superado não constam na referida apresentação, porém são mostradas discursivamente na sequência.

Quadro 2 - Três projetos em comparação

\begin{tabular}{|c|c|c|c|}
\hline & E1 & E2 & $\mathbf{E 3}$ \\
\hline $\begin{array}{l}\text { Problema } \\
\text { encontrado }\end{array}$ & $\begin{array}{l}\text { Projeto desenvolvido no } \\
\text { final de 2015, após } \\
\text { identificar a ausência de um } \\
\text { código de ética na empresa. }\end{array}$ & $\begin{array}{l}\text { Projeto proposto e } \\
\text { desenvolvido em 2018/2019, } \\
\text { após identificar que havia } \\
\text { oportunidade para redução } \\
\text { de custos com as viagens } \\
\text { corporativas da empresa. }\end{array}$ & $\begin{array}{l}\text { Projeto desenvolvido em } \\
\text { 2008, quando identificada a } \\
\text { falta de indicadores de } \\
\text { desempenho para os } \\
\text { profissionais da área } \\
\text { secretarial da empresa. }\end{array}$ \\
\hline $\begin{array}{l}\text { Objetivo do } \\
\text { projeto }\end{array}$ & $\begin{array}{l}\text { Criação de um código de } \\
\text { ética para ser seguido pelos } \\
\text { funcionários, visando } \\
\text { informá-los quais eram as } \\
\text { expectativas da empresa em } \\
\text { relação a conduta de cada } \\
\text { um. }\end{array}$ & $\begin{array}{l}\text { Contratação das viagens } \\
\text { corporativas com maior } \\
\text { antecedência, a fim de gerar } \\
\text { economia à empresa. }\end{array}$ & $\begin{array}{l}\text { Criação de indicadores de } \\
\text { desempenho para os } \\
\text { profissionais de secretariado } \\
\text { da organização, com a } \\
\text { finalidade de promover } \\
\text { maior visibilidade da } \\
\text { categoria na empresa. }\end{array}$ \\
\hline $\begin{array}{l}\text { Etapas } \\
\text { do projeto }\end{array}$ & $\begin{array}{l}\text { 1) Identificação do } \\
\text { problema; 2) consulta a } \\
\text { diversos códigos de ética, } \\
\text { documentos e temas afins; 3) } \\
\text { elaboração do planejamento } \\
\text { do projeto; 4) levantamento } \\
\text { das problemáticas } \\
\text { envolvidas; 5) escolha da } \\
\text { equipe que ajudaria na } \\
\text { implementação do projeto } \\
\text { após o aval dos gestores; 6) } \\
\text { desenvolvimento do projeto; } \\
\text { e 7) apresentação dos } \\
\text { resultados. }\end{array}$ & $\begin{array}{l}\text { 1) Identificação do objetivo } \\
\text { do projeto com vistas a } \\
\text { apresentar uma solução para } \\
\text { um problema da empresa; 2) } \\
\text { estabelecimento de metas; 3) } \\
\text { descrição de como seriam } \\
\text { realizadas as ações } \\
\text { estabelecidas no projeto; e 4) } \\
\text { controle dos resultados por } \\
\text { intermédio de planilhas e } \\
\text { apresentações mensais das } \\
\text { metas alcançadas. }\end{array}$ & $\begin{array}{l}\text { 1) Identificação do } \\
\text { problema; 2) criação de um } \\
\text { esboço do projeto, } \\
\text { contemplando os problemas } \\
\text { que poderiam surgir; } 3 \text { ) } \\
\text { tabulação dos problemas } \\
\text { versus soluções; 4) } \\
\text { apresentação do pré-projeto } \\
\text { para o seu gestor imediato; } \\
\text { 5) aprovação pelo gestor; } 6 \text { ) } \\
\text { elaboração dos indicadores } \\
\text { de desempenho; e 7) } \\
\text { desenvolvimento e } \\
\text { implantação do projeto. }\end{array}$ \\
\hline $\begin{array}{l}\text { Resultados } \\
\text { obtidos }\end{array}$ & $\begin{array}{l}\text { Foi criada na empresa uma } \\
\text { área voltada especificamente } \\
\text { à criação de novos projetos e } \\
\text { processos. }\end{array}$ & $\begin{array}{l}\text { As reduções foram } \\
\text { alcançadas e, a partir disso, } \\
\text { criou-se uma nova política } \\
\text { de viagens, com a finalidade } \\
\text { de atender os critérios } \\
\text { estabelecidos no projeto. }\end{array}$ & $\begin{array}{l}\text { A partir desse projeto, outros } \\
\text { foram propostos na empresa } \\
\text { pela secretária-gestora e } \\
\text { demais colaboradores. }\end{array}$ \\
\hline
\end{tabular}

Fonte: Elaborado pelas pesquisadoras (2021).

Ao comparar os três relatos, contatou-se que, embora não de modo metodológico, as entrevistadas seguiram as fases processuais da gestão de projeto, conforme descrito no PMBoK (2017), a saber: iniciação; planejamento; execução; monitoramento e controle; encerramento. 
Ressalta-se que percorrer tal ciclo foi fundamental para o êxito dos três projetos relatados, pois possibilitou que ajustes fossem feitos no decorrer das ações por meio da mobilização de competências.

No que se refere ao maior desafio encontrado e como foi superado, E1 afirmou que a comunicação entre todas as partes envolvidas foi o aspecto que demandou maior atenção, porque requeria diferentes comunicados a depender do interlocutor (superiores, subordinados ou pares). Para superar esse desafio, buscou estabelecer uma comunicação, atentando para evitar conflitos e não interferir, além do necessário, no exercício individual e coletivo dos colaboradores.

E2, por sua vez, relatou que, mesmo convencidos de que as reduções de custos seriam concretas, muitos colaborares demoraram para se ajustar ao novo processo de solicitação das viagens corporativas com maior antecedência. Para superar essa resistência, E2 realizou um trabalho de conscientização entre os viajantes e, aos poucos, o processo foi internalizado por todos.

E3 apontou que exercer o papel de liderança foi o maior desafio com o qual se deparou durante o projeto. Isso porque em uma equipe é natural que as pessoas tenham crenças e visões diferentes. A diversidade é bastante benéfica em um grupo, conforme declarado por E3, mas administrar as diferenças torna o processo mais complexo, ainda que seja uma ação inerente ao conjunto de ações a serem geridas.

\subsection{COMPETÊNCIAS MOBILIZADAS E ADQUIRIDAS COM A GESTÃO DOS PROJETOS}

Recorrendo-se novamente ao PMBoK (2017), evidencia-se que as competências de um gestor de projetos seguem um "Triângulo de Talentos", descrito por intermédio dos seguintes aspectos, conforme se apresenta no Quadro 3:

Quadro 3 - Triângulo de Talentos

\begin{tabular}{|l|l|}
\hline \multicolumn{1}{|c|}{ Ações } & \multicolumn{1}{c|}{ Competências } \\
\hline Gerenciamento de projetos técnicos & $\begin{array}{l}\text { Conhecimentos, comportamentos e habilidades necessários } \\
\text { para a execução da função de gerenciador. }\end{array}$ \\
\hline Liderança & $\begin{array}{l}\text { Habilidades para orientar, motivar e dirigir equipes e atingir } \\
\text { as metas. }\end{array}$ \\
\hline Gerenciamento estratégico e de negócios & $\begin{array}{l}\text { Conhecimento da organização e da área na qual irá atuar para } \\
\text { que se atinja da melhor maneira os resultados estabelecidos. }\end{array}$ \\
\hline
\end{tabular}

Fonte: Adaptado de PMBoK (2017).

Revista Expectativa, Toledo/PR, v.20, n. 4, p. 35-60, out./dez., 2021. 
Com o objetivo de explorar o tema competências, cuja importância é ressaltada no “Triângulo de Talentos" aqui recobrado, foi proposto o último do tópico da entrevista, sendo que para o seu desenvolvimento foram feitas duas perguntas às entrevistadas.

Questionou-se, em um primeiro momento, quais foram as principais competências que precisaram mobilizar para o gerenciamento dos seus projetos. E1 informou que precisou mobilizar competências voltadas à comunicação e organização. Esclareceu que mesmo não se tratando de uma competência em si, foi necessário mobilizar valores morais, ou seja, a ética, para a condução do projeto. E2 apontou que, para gerenciar o seu projeto, foi necessário estudo demasiado, persistência e organização. Enquanto a E3 expôs ter sido necessário buscar conhecimento acerca das questões que envolviam o projeto (indicadores de desempenho), construir uma relação de confiança entre todos os envolvidos, bem como manter-se responsável pelo projeto do início ao fim.

No segundo e último momento da entrevista, as participantes foram questionadas sobre as mudanças (ou possíveis mudanças) que ocorreram nas competências pessoais e profissionais ao longo do projeto. E1 informou que se tornou mais observadora, passou a perceber com maior atenção as atividades exercidas pelos setores e colaboradores, a fim de visualizar oportunidades de melhoria e, consequentemente, a proposição e gestão de novos projetos. Além disso, E1 pontuou que os erros e desafios que apareceram ao longo do projeto proposto oportunizaram a ela adquirir enriquecimento intelectual e emocional. E2 declarou ter constatado que, após a finalização do projeto, objetivos bem delimitados, tanto profissionais quanto pessoais, puderam ser alcançados a partir do desenvolvimento e da mobilização de novas e antigas competências. Por fim, E3 declarou que a liderança foi uma das competências mais desenvolvidas e, além disso, foi possível ampliar suas capacidades relativas ao trabalho em equipe e relacionamento interpessoal.

A partir das declarações das entrevistadas, constatou-se que competências intraempreendedoras, tais quais são tratadas e divididas em Dornellas (2005) - técnicas, gerenciais e pessoais -, precisaram ser mobilizadas e outras foram adquiridas e desenvolvidas ao longo da gestão dos projetos apresentados neste estudo.

Dentre as competências técnicas destaca-se a organização, citada por E1 e E2, a liderança e a gestão de pessoas, citadas por E3. No que tange às competências gerenciais, ou seja, a capacidade de criar e gerir novos negócios (DORNELLAS, 2005), ainda que não 
declaradas explicitamente, é possível inferir que as três secretárias entrevistadas precisaram mobilizá-las e/ou desenvolvê-las para que pudessem estar à frente dos projetos propostos e, conforme apresentado no Quadro 2, contribuindo com resultados satisfatórios ao agregar valor para as suas empresas. As competências pessoais - observação (E1), persistência (E2) e responsabilidade (E3) -, também foram referidas pelas entrevistadas.

Notou-se que algumas competências se coadunaram, porém uma merece destaque, pois foi apontada pelas três participantes: a capacidade de aprender ao longo da vida ou lifelong learning, para apresentar o termo em língua inglesa assim como foi originado e amplamente disseminado. Todas mencionaram que foi preciso buscar conhecimento para que pudessem intraempreender. Nessa direção, o conhecimento não é compreendido somente como um dos pilares da noção de competência (MARINHO, 2015). Trata-se, neste caso, de uma competência per si que permite a um indivíduo investir ativamente em seu desenvolvimento pessoal e profissional de forma proativa e constante (SCHLOCHAUER, 2021) - tal qual foi necessário para as três secretárias, gestoras de seus projetos e participantes do presente estudo.

\section{CONSIDERAÇÕES FINAIS}

Há algum tempo, para uma adequada atuação na área secretarial, é requerido a Secretários(as) Executivos(as) um perfil que esteja pautado nos princípios da flexibilidade, a fim de atender os propósitos organizacionais, em constante mudança pelas leis do mercado, e também individuais. Nesse sentido, é inegável que o desenvolvimento e a mobilização de novas competências, ligadas direta ou indiretamente à profissão, possam vir a garantir a esses profissionais um desempenho que vai ao encontro dos resultados esperados pela empresa em que atuam.

Ao buscar atender as demandas corporativas, a depender dos fatores higiênicos (extrínsecos) e/ou motivacionais (intrínsecos), bem como das competências intraempreendedoras de cada profissional, é possível que o(a) Secretário(a) Executivo(a) constate problemas e/ou oportunidades e proponha encaminhamentos para tais, culminando em projetos.

A fim de compreender quais fatores levam os profissionais de secretariado executivo a propor um projeto e, como consequência, tornarem-se responsáveis pela sua gestão na empresa em que atuam, é que se formulou a pergunta deste estudo. Como resultado, tanto em resposta

Revista Expectativa, Toledo/PR, v.20, n. 4, p. 35-60, out./dez., 2021. 
ao problema de pesquisa como em direção ao objetivo geral do trabalho, foi possível verificar que os fatores motivacionais tiveram maior preponderância em comparação aos fatores higiênicos, tendo como base o levantamento bibliográfico e, posteriormente, a coleta de dados, cujos resultados foram cruzados.

Desse modo, afirma-se que o objetivo geral foi cumprido. Após a análise dos dados, contatou-se que todos os questionamentos acerca de motivação, gerenciamento de projetos e competências foram respondidos pelas entrevistadas de acordo as fontes pesquisadas e possibilidades iniciais.

Os objetivos específicos foram igualmente atendidos, uma vez que, a partir da metodologia escolhida, foi possível examinar que os profissionais da área secretarial têm um perfil compatível com o que se espera de um gestor de projetos. No entanto, para o gerenciamento de um projeto, é necessário, independentemente do nível hierárquico, que todo e qualquer profissional, encontre condições favoráveis e tenha competências intraempreendedoras para tal feito, tornando-se gestores e, como consequência, protagonistas em suas áreas - como foi o caso das secretárias cujas entrevistas foram descritas no decorrer desta pesquisa.

Ainda em consonância com objetivos específicos deste estudo, dentre as competências necessárias para a gestão de um projeto, verificou-se que os profissionais entrevistados precisaram desenvolver e mobilizar competências de ordem técnica, gerencial e pessoal, conforme divisão proposta em Dornelas (2005), particularmente àquelas que dizem respeito à comunicação, organização e responsabilidade.

Embora a coleta de dados tenha contemplado as respostas de apenas três profissionais da área secretarial, o que poderia ser considerada uma limitação relevante, cumpre reforçar, conforme explicado na seção "Metodologia" deste estudo, que as participantes são reconhecidas como referências positivas, pois exercem a profissão com notório destaque no meio secretarial brasileiro. Além disso, dados de pesquisa, quando devidamente apurados, contribuem para o contex to científico.

Em decorrência a essa possível limitação, acredita-se que este trabalho possa incentivar futuras pesquisas, acerca do tema gestão de projetos, com um número maior de profissionais da área secretarial. Sugere-se, desse modo, ampliar a discussão sobre o papel das empresas no que diz respeito ao incentivo para a proposição de projetos e o desenvolvimento de competências intraempreendedoras por seus(suas) Secretários(as) Executivos(as), uma vez que se constatou,

Revista Expectativa, Toledo/PR, v.20, n. 4, p. 35-60, out./dez., 2021. 
neste estudo, a importância e o impacto da gestão de excelentes projetos pela categoria secretarial.

Ademais, como contribuição ao Secretariado Executivo, espera-se que os profissionais da área, a partir das discussões trazidas neste estudo, percebam quão estratégicas são as competências que precisam mobilizar no seu dia a dia e como essas podem ser utilizadas para empreendimentos de maior grandeza nas organizações. Ao despertarem para esse fato, certamente mais profissionais poderão vir a ser referências e protagonistas no meio secretarial e no mundo do trabalho.

\section{REFERÊNCIAS}

BARDIN, L. Análise de conteúdo. Lisboa: Edições 70, 2011.

CAMARGO, F. A. A importância percebida de competências financeiras para profissionais de secretariado. 36 f. Dissertação (Programa de Mestrado Profissional em Administração) - Centro Universitário Álvares Penteado, Fundação Escola de Comércio Álvares Penteado, São Paulo, 2017.

CAVALCANTI, M.; FARAH, O. E.; MARCONDES, L. P. Gestão estratégica de negócios: estratégias de crescimento e sobrevivência empresarial. 3. ed. São Paulo: Cengage Learning, 2018.

CHIAVENATO, I. Introdução à teoria geral da administração. 9. ed. São Paulo: Manole, 2014.

CLASSIFICAÇÃO BRASILEIRA DE OCUPAÇÕES [CBO]. CBO 2523-05. (2010). Disponível em: https://www.ocupacoes.com.br/cbo-mte/252305-secretaria-o-executiva-o. Acesso em: 21 outubro 2020.

DAFT, R. F. Administração. 3. ed. São Paulo: Cengage Learning, 2017.

DORNELAS, J. C. A. Transformando ideias em negócios. 2. ed. Rio de Janeiro: Elsevier, 2005.

FARAH, O. E., CAVALCANTI, M., MARCONDES, L. P. Empreendedorismo estratégico: criação e gestão de pequenas empresas. 2. ed. São Paulo: Cengage Learning, 2017.

FIGUEIREDO, F. C., FIGUEIREDO, H. C. M. Dominando gerenciamento de projetos com MS Project 2002. São Paulo: Ciência Moderna, 2013. 
FLEURY, M. T. L.; FLEURY, A. Construindo o conceito de competência. Revista de Administração Contemporânea, Curitiba, v. 5, p. 183-196, 2001. Disponível em: http://www.scielo.br/scielo.php?pid=S1415-65552001000500010\&script=sci_arttext. Acesso em: 14 set. 2021.

FLICK, U. Introdução à metodologia de pesquisa: um guia para iniciantes. Porto Alegre: Penso, 2013.

FREITAS, M. E. de. Cultura organizacional: evolução e crítica. São Paulo: Cengage Learning, 2009.

FUMAGALI, L. A. W. Intraempreendedorismo: um estudo das relações entre cultura organizacional e a capacidade de empreender nas empresas. In: SIMPÓSIO DE GESTÃO DA INOVAÇÃO TECNOLÓGICA DA ANPAD, 2008. Anais [...]. Brasília, 2008.

GIDO, J.; CLEMENTS, J.; BEKER, R. Gestão de projetos. 3. ed. São Paulo: Cengage Learning, 2018.

GRIFFIN, W. R.; MOORHEAD, G. Comportamento organizacional: gestão de pessoas e organizações. São Paulo: Cengage Learning, 2015.

HIGA, A. J. L. O.; LIMA, M. C.; SANTOS, N. K. Como ocorre o intraempreendedorismo na gestão secretarial? Trabalho de conclusão de curso (Graduação em Secretariado Executivo) - Centro Universitário Álvares Penteado, Fundação Escola de Comércio Álvares Penteado, São Paulo, 2017.

IRELAND, L. R., CLELAND, D. I. Gerenciamento de projetos. 2. ed. São Paulo: LTC, 2007.

KURATKO, D. F. Empreendedorismo: teoria, processo, prática. 10. ed. São Paulo: Cengage Learning, 2016.

LAVILLE, C., DIONNE, J. A construção do saber: manual de metodologia da pesquisa em ciências humana. Porto Alegre: Artmed, 1999.

LE BOTERF, G. Desenvolvendo a competência dos profissionais. 3. ed. Tradução: P. C. R. Reuillard. Porto Alegre: Artmed, 2007.

LOBOS, J. (1975). Teorias sobre a motivação no trabalho. Revista de Administração de Empresas, São Paulo, SP, v. 15, n. 2, p. 17-25. Disponível em:

https://www.scielo.br/scielo.php?script=sci_arttext\&pid=S0034-75901975000200002. Acesso em: 13 março 2020.

MARCONI, M. A.; LAKATOS, E. M. Fundamentos de metodologia científica. 5. ed. São Paulo: Atlas, 2003. 
MARINHO, A. P. (Org.). Competências especiais para o desenvolvimento contínuo do profissional de secretariado executivo. São Paulo: SinSesp, 2014.

MARINHO, A. P. (Org.). Framework do plano de carreira do profissional de secretário. São Paulo: SinSesp, 2015.

MARQUES, J. C. Comportamento organizacional. São Paulo: Cengage Learning, 2016.

MARTINS, G. DE A.; THEÓPHILO, C. R. Metodologia da investigação científica para ciências sociais aplicadas. 3. ed. São Paulo: Atlas, 2016.

MAZULO, R.; LIENDO, S. Secretária: rotina gerencial, habilidades comportamentais e plano de carreira. São Paulo: SENAC, 2010.

NEIVA, E. G.; D'ELIA, M. E. S. As novas competências do profissional de secretariado. 3. ed. São Paulo: IOB Folhamatic, 2014.

PMBoK. Guia do conhecimento e gerenciamento de projetos. 6. ed. Pensilvânia: Project Management Institute, 2017.

RABECHINI JR., R. O gerente de projetos na empresa. 3. ed. São Paulo: Atlas, 2008.

SCHLOCHAUER, C. Lifelong learners - o poder do aprendizado contínuo: aprenda a aprender e mantenha-se relevante em um mundo repleto de mudanças. São Paulo: Gente, 2021.

TODOROV, M. do C. A. Competências do secretariado executivo na gestão de projetos socioambientais sob a perspectiva do gerente de projetos. Dissertação (Programa de Mestrado Profissional em Administração - Gestão de Projetos) - Universidade Nove de Julho, São Paulo, 2015.

VALLE, A. B. do.; SOARES, C. A. P.; FINOCCHIO JUNIOR, J.; SILVA, L. S. da. Fundamentos do gerenciamento de projetos. Rio de Janeiro: FGV, 2010.

VARGAS, R. Gerenciamento de projetos: estabelecendo diferenciais competitivos. 6 . ed. Rio de Janeiro: Brasport, 2003.

VECCHIO, R. P. Comportamento organizacional. São Paulo: Cengage Learning, 2012.

WILLIAMS, C. ADM: princípios de administração. 2. ed. São Paulo: Cengage Learning, 2017.

ZWICKER, A. M.; OLIVEIRA, L. R. de; LÖBLER, M. L. Teorias de Herzberg e McGregor: um comparativo entre os setores administrativos público e privado. Revista Sociais e Humanas, Santa Maria, v. 31, p. 108-128, 2018. Disponível em: https://periodicos.ufsm.br/sociaisehumanas/article/view/30999/pdf. Acesso em: 14 set. 2021. 